\title{
Removal of phenol and bisphenol-A catalyzed by laccase in aqueous solution
}

\author{
Zahra Asadgol ${ }^{1,2}$, Hamid Forootanfar ${ }^{3}$, Shahla Rezaei ${ }^{1}$, Amir Hossein Mahvi $i^{2,4,5^{*}}$ and Mohammad Ali Faramarzi ${ }^{{ }^{*}}$
}

\begin{abstract}
Background: Elimination of hazardous phenolic compounds using laccases has gained attention during recent decades. The present study was designed to evaluate the ability of the purified laccase from Paraconiothyrium variabile $(P \vee \mathrm{L})$ for elimination of phenol and the endocrine disrupting chemical bisphenol A. Effect of laccase activity, $\mathrm{pH}$, and temperature on the enzymatic removal of the mentioned pollutants were also investigated.

Results: After 30 min treatment of the applied phenolic pollutants in the presence of $P V L(5 \mathrm{U} / \mathrm{mL}), 80 \%$ of phenol and $59.7 \%$ of bisphenol A was removed. Increasing of laccase activity enhanced the removal percentage of both pollutants. The acidic pH of 5 was found to be the best $\mathrm{pH}$ for elimination of both phenol and bisphenol A. Increasing of reaction temperature up to $50^{\circ} \mathrm{C}$ enhanced the removal percentage of phenol and bisphenol A to $96.3 \%$ and $88.3 \%$, respectively.
\end{abstract}

Conclusions: To sum up, the present work introduced the purified laccase of $P$. variabile as an efficient biocatalyst for removal of one of the most hazardous endocrine disruptor bisphenol A.

Keywords: Removal, Laccase, Paraconiothyrium variabile, Pollutant, Bisphenol A

\section{Introduction}

Phenol is one of the most environmentally hazardous pollutants which increasingly been applied by industries like petrochemical, coking, plastics, paper and oil refineries, as well as phenolic resin industries $[1,2]$. Poor solubility and biodegradability, long term ecological damage and high toxicity of phenol and its derivatives led to calls by Environmental Protection Agency (EPA) for lowering phenol concentration in the wastewater to less than $1 \mathrm{mg} / \mathrm{mL}$ before discharging them into the water reservoirs [3]. The estrogenic action and impacts of the bisphenol $\mathrm{A}$ (4,4'-isopropylidenediphenol, BPA), an industrial chemical which is widely used for the synthesis of polycarbonate plastics and epoxy resins, on female reproductive tract introduced BPA as an endocrine disrupting chemical (EDC) $[4,5]$. The role of BPA exposure in development of prostate and breast cancers, reduction of human sperm counts, alteration of immune functions, prevalence of

\footnotetext{
* Correspondence: ahmahvi@yahoo.com; faramarz@tums.ac.ir

${ }^{2}$ Department of Environmental Health Engineering, School of Public Health, Tehran University of Medical Sciences, Tehran, Iran

'Department of Pharmaceutical Biotechnology, Faculty of Pharmacy and Biotechnology Research Center, Tehran University of Medical Sciences, P.O. Box 14155-6451, Tehran 14176, Iran

Full list of author information is available at the end of the article
}

obesity and decrease fertility in fish and mammals has been demonstrated by some studies [5,6]. So, various physicochemical processes like activated carbon adsorption, solvent extraction, chemical oxidation and electrochemical methods have been developed to remove phenolic compounds from wastewaters [5,7-13]. However, wide applications of some of these remediation strategies have been limited due to problems such as high cost, low efficiency, and generation of toxic by-products $[14,15]$. On the other hand, advantages of biological techniques including biodegradation of xenobiotics using living microorganisms like algae [16], bacteria and fungi and/or their purified oxidizing enzymes both in free $[17,18]$ and immobilized form [19-22] as well as biosorption of organic pollutants $[1,23]$ introduced this field as a novel area for removal of hazardous compounds.

Laccases (benzenediol: oxygen oxidoreductase, EC 1.10.3.2) are copper containing oxidases catalyzing the oxidation of a wide range of aromatic substrates including phenol derivatives, benzenethiols, polyphenols [24] and polycyclic aromatic hydrocarbons (PAHs) [25]. In recent decades, laccase-producing microorganisms, especially white-rot fungi $[25,26]$ have been employed for biological treatment of different pollutants [27]. Biodegradation of 
brominated phenols using cultures and laccase of Trametes versicolor was investigated by Uhnakova et al. [26]. Zhang et al. [24] studied on degradation of 2,4-dichlorophenol (2,4-DCP), 4-chlorophenol ( $\rho-C P)$, and 2-chlorophenol catalyzed by laccase from Coriolus versicolor.

The aim of the present study was to investigate on the ability of the purified laccase from the ascomycete Paraconiothyrium variabile, a newly isolated laccase-producing ascomycete from soil, for elimination of phenol and bisphenol A. Effect of parameters such as laccase activity, $\mathrm{pH}$, and temperature on removal of pollutants was also studied.

\section{Materials and methods}

\section{Laccase and chemicals}

The produced laccase of $P$. variabile was purified from fungal culture broth based on the method described by Forootanfar et al. [28] and applied in pollutant removal experiments. Phenol, bisphenol A (BPA), and 4-aminoantipyrine (4-AAP) were purchased from Merck (Darmstadt, Germany). 2,2' -Azinobis-(3-ethylbenzthiazoline-6-sulphonate) (ABTS) was obtained from Sigma-Aldrich (St. Louis, $\mathrm{MO}, \mathrm{USA}$ ). All other chemicals were of analytical grade.

\section{Determination of laccase activity}

Oxidation of ABTS as a laccase substrate was used to determine the laccase activity [29,30]. In brief, $0.5 \mathrm{~mL}$ of enzyme sample was added to $0.5 \mathrm{~mL}$ of ABTS solution (5 $\mathrm{mM}$ in $0.1 \mathrm{M}$ citrate buffer, $\mathrm{pH} 4.5$ ) and incubated at $37^{\circ} \mathrm{C}$ and $120 \mathrm{rpm}$ for $10 \mathrm{~min}$. Change in absorbance at $420 \mathrm{~nm}$ was monitored by a UV/vis spectrophotometer (UVD 2950, Labomed, Culver City, USA) and the laccase activity was calculated using the molar extinction coefficient of ABTS $\left(\varepsilon_{420}=36,000 \mathrm{M}^{-1} \mathrm{~cm}^{-1}\right)$. One unit of laccase activity was defined as the amount of enzyme required to oxidize $1 \mu \mathrm{mol}$ of substrate per minute [31].

\section{Removal studies}

In order to study on the ability of the purified laccase for elimination of phenolic pollutants, the reaction mixture (final volume of $3 \mathrm{~mL}$ ) was prepared as follow: $1 \mathrm{~mL}$ of phenol or BPA solution (final concentration of $4 \mathrm{mM}$ ) was added to $1 \mathrm{~mL}$ citrate buffer (20 mM pH 5) followed by introducing of the purified laccase (final concentration of $5 \mathrm{U} / \mathrm{mL}$ ) to the reaction mixture and incubation at $35^{\circ} \mathrm{C}$ and $50 \mathrm{rpm}$ for $40 \mathrm{~min}$. Samples were taken every $10 \mathrm{~min}$ and analyzed for remaining concentration of phenolic pollutants. The negative control was designed by inserting of heat-inactivated laccase to the reaction mixture. Each experiment was performed in triplicate and mean of the obtained results were reported.
Determination of phenol and bisphenol A concentration Concentration of phenolic pollutants was measured using a colorimetric assay in presence of 4-AAP as a primary amine [6]. Briefly, the reaction mixture was prepared by addition of $700 \mu \mathrm{L}$ of phosphate buffer $(0.1 \mathrm{M}$ $\mathrm{pH} 8), 300 \mu \mathrm{L}$ of laccase-treated phenol or BPA sample, $10 \mu \mathrm{L}$ of 4 -AAP $(0.1 \mathrm{M})$ and $10 \mu \mathrm{L}$ potassium ferricyanide solution $(0.2 \mathrm{M})$ followed by incubation at $25^{\circ} \mathrm{C}$ and $100 \mathrm{rpm}$ for $15 \mathrm{~min}$. The absorbance of the reaction mixture was then measured at $506 \mathrm{~nm}$ and the phenol or BPA concentration was determined from the obtained standard curve.

\section{Effect of laccase activity on the removal of phenolic pollutants}

The effect of laccase activity on the removal of phenol or BPA was studied by adding of enzyme solution (1, 5, 10 and $20 \mathrm{U} / \mathrm{mL}$ in citrate buffer $20 \mathrm{mM} \mathrm{pH} \mathrm{5)} \mathrm{to} \mathrm{the} \mathrm{phe-}$ nolic pollutant solutions (final concentration of $4 \mathrm{mM}$ ) and incubation at $35^{\circ} \mathrm{C}$ and $50 \mathrm{rpm}$ for $30 \mathrm{~min}$. The reaction mixture was then analyzed for remained phenolic pollutant concentration as described above.

\section{The effect of $\mathrm{pH}$ on laccase-mediated removal}

After adjusting the initial $\mathrm{pH}$ of the phenolic pollutant solution (final concentration of $4 \mathrm{mM}$ ) using $20 \mathrm{mM}$ citrate-phosphate buffer between $3-7$, the purified laccase $(5 \mathrm{U} / \mathrm{mL})$ was added to the reaction mixture and incubated at $35^{\circ} \mathrm{C}$ and $50 \mathrm{rpm}$ for $30 \mathrm{~min}$. The pollutant concentration was then monitored as previously described.

\section{The influence of temperature on enzymatic removal}

The effect of temperature on enzymatic elimination of pollutants was studied by incubating $4 \mathrm{mM}$ of the phenolic pollutant solution (in citrate buffer $20 \mathrm{mM} \mathrm{pH}$ 5) in the presence of laccase $(5 \mathrm{U} / \mathrm{mL})$ at temperature range of $30-70^{\circ} \mathrm{C}$.

\section{Results and discussion}

\section{Pollutant elimination by the purified laccase}

As shown in the time course of phenolic pollutant elimination curves (Figure 1) the purified $P v \mathrm{~L}$ removed $29.6 \%$ and $44.3 \%$ of BPA and phenol, respectively after $10 \mathrm{~min}$ treatment. After $30 \mathrm{~min}$, the removal percentages increased by $59.7 \%$ and $80 \%$ in the case of BPA and phenol, respectively (Figure 1). No elimination was detected in the case of negative controls. The enzymatic removal of phenol and related hazardous compounds especially the endocrine disruptor compound (bisphenol A) discharged from industrial effluents into the environment has received more attention during recent decades [32,33]. Potential of $P v \mathrm{~L}$ for removing of a wide range of chemicals including chlorophenols, synthetic dyes and benzodiazepines have been shown in recent studies [14,15,22,27]. 


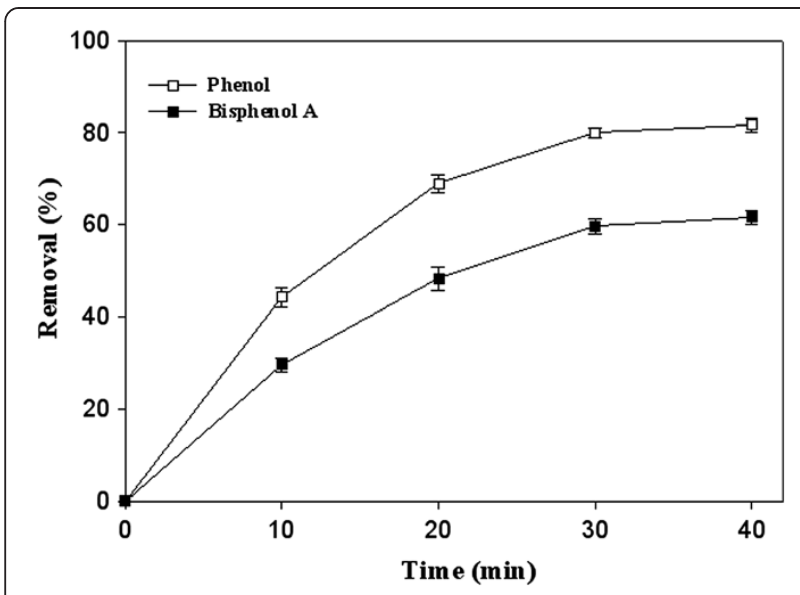

Figure 1 Time courses of phenol and bisphenol A removal (initial concentration of $4 \mathrm{mM}$ ) using the purified laccase of $P$. variabile $(5 \mathrm{U} / \mathrm{mL})$ dissolved in citrate buffer $20 \mathrm{mM} \mathrm{pH} 5$.

The present study showed that both applied phenolic pollutants (initial concentration of $4 \mathrm{mM}$ ) was eliminated using the purified laccase of $P$. variabile after $30 \mathrm{~min}$ incubation. Kurniawati et al. [33] reported about removal of phenol (initial concentration of $500 \mu \mathrm{M}$ ) after $6 \mathrm{~h}$ incubation in presence of the purified laccase from Trametes versicolor. The purified laccase of Fusarium incarnatum UC-14 hosted in the reversed micelle was able to remove 91.43\% of bisphenol A (200 ppm) after $2 \mathrm{~h}$ incubation [5].

\section{The effect of laccase activity on removal of phenolic} pollutants

The pattern of removal of pollutants by increasing of laccase activity from $1 \mathrm{U} / \mathrm{mL}$ to $20 \mathrm{U} / \mathrm{mL}$ is illustrated in Figure 2. In the present study, it was showed that elimination of both phenol and bisphenol A increased when laccase activity was enhanced. Same results was

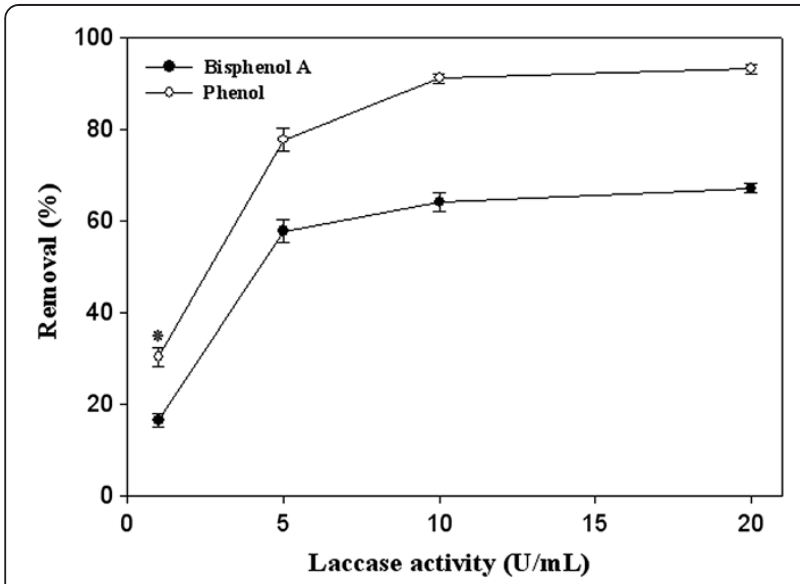

Figure 2 Effect of laccase activity on removal percentage of phenolic pollutants (initial concentration of $4 \mathrm{mM}$ ) after $30 \mathrm{~min}$ enzymatic treatment.

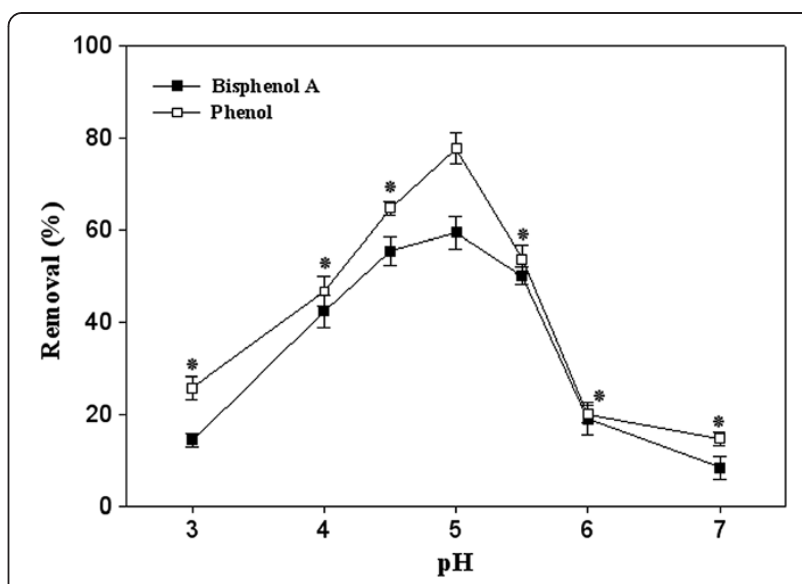

Figure 3 Influence of pH alteration on removal of bisphenol A and phenol in presence of the purified laccase of $P$. variabile $(5 \mathrm{U} / \mathrm{mL})$ after 30 min enzymatic treatment.

observed in study of Okazaki et al. [34], which indicated that increasing of laccase concentration (originated from Coriolus versicolor) from 0 to $50 \mu \mathrm{g} / \mathrm{mL}$ enhanced BPA removal to $100 \%$. Application of the purified laccase from Trichoderma atroviride $(0.3 \mathrm{U} / \mathrm{mL})$ for elimination of phenolic pollutants including 2,4-dichlorophenoxyacetic acid, 4-chlorophenol, o-cresol or and catechol led to $21 \%, 28 \%, 100 \%$ and $100 \%$ removal of pollutants, respectively after $24 \mathrm{~h}$ incubation [35].

\section{The influence of $\mathrm{pH}$ on pollutant removal}

As illustrated in Figure 3, both of studied pollutants represented maximum removal percentages (77.7\% and 59.3\% in the case of phenol and BPA, respectively) at $\mathrm{pH} 5$, which was previously introduced as the optimum $\mathrm{pH}$ for the activity of the purified laccase from $P$. variabile [28]. Majority of the fungal laccases optimally act in acidic $\mathrm{pH}$

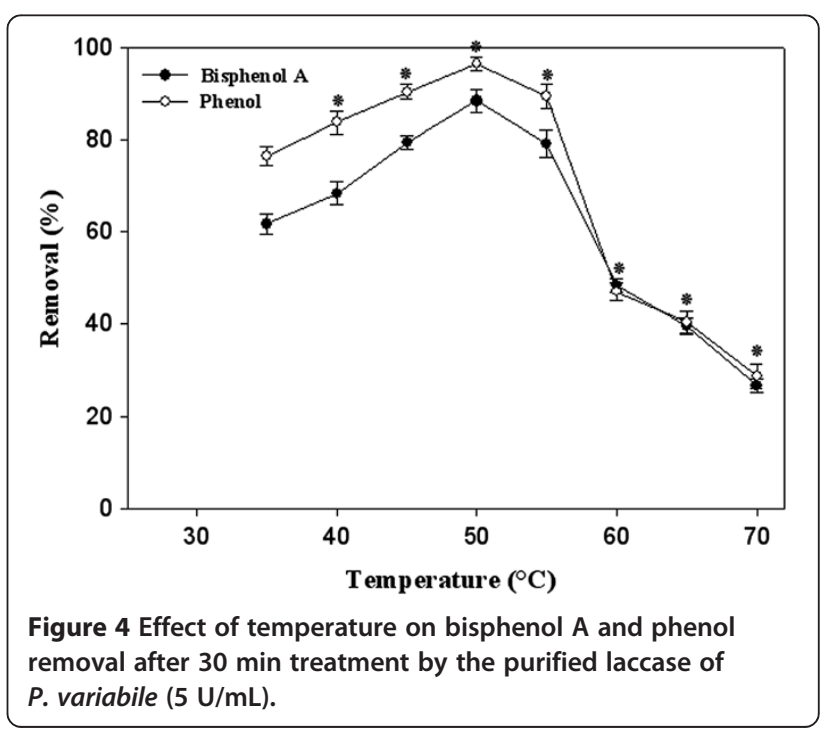


[36]. In the study of Chhaya and Gupte [5], who evaluated the activity of laccase from Fusarium incarnatum UC-14 toward BPA, the $\mathrm{pH}$ value of 6 was introduced as optimal $\mathrm{pH}$ for removal of bisphenol A. study of Liu et al. [37] showed that acidic environment ( $\mathrm{pH}$ 6) was the best condition for phenol removal using the recombinant laccase of T. versicolor.

\section{The effect of temperature on laccase-mediated pollutant removal}

The optimum temperature for the elimination of phenol (96.3\% removal) and BPA (88.3\% removal) was found to be $50^{\circ} \mathrm{C}$ (Figure 4). This temperature is the optimum temperature of $P v \mathrm{~L}$ activity determined by Forootanfar et al. [28]. At elevated temperature of $60^{\circ} \mathrm{C}$ the removal percentage of phenol and BPA in presence of $P v \mathrm{~L}$ dropped to $47 \%$ and $48.3 \%$, respectively. These results were in agreement with the findings of Kurniawati and Nicell [33], who determined maximum laccase-assisted phenol elimination between $40^{\circ} \mathrm{C}$ and $50^{\circ} \mathrm{C}$ and a sharp decrease in pollutant removal was observed above $60^{\circ} \mathrm{C}$. In the study of Kim et al. [4] maximum of bisphenol A degradation (67\%) using the laccase of Trametes versicolor $(0.15 \mathrm{U} / \mathrm{mL})$ was achieved at temperature of $45^{\circ} \mathrm{C}$. Most of the fungal laccases maximally act in the temperature range of $50-70^{\circ} \mathrm{C}$, although the maximum activity of laccase from G. lucidum was at $25^{\circ} \mathrm{C}$ [36].

\section{Conclusion}

The purified laccase of $P$. variabile applied for removal of phenol and bisphenol A. PvL was efficiently eliminated both applied pollutants after $30 \mathrm{~min}$ treatment. Maximum of removal percent in the case both phenolic pollutants was obtained at optimum $\mathrm{pH}$ and temperature of the $P v \mathrm{~L}$. To sum up, the results of the present investigation candidate the purified $P v \mathrm{~L}$ for removal of phenolic pollutants. However, more study should be conducted to find out about probable produced metabolites.

\section{Competing interests}

The authors declare that they have no competing interests.

\begin{abstract}
Authors' contributions
ZA carried out the elimination studies of phenol and bisphenol A. Production and purification of laccase from $P$. variabile culture broth was performed by SR and HF, respectively. AHM contributed in writing of the manuscript, elimination studies and analyzing of data. MAF involved in purchasing of required materials and instruments, designing of removal experiments, analyzing of data and reviewing of the manuscript. All authors read and approved the final manuscript.
\end{abstract}

\section{Acknowledgement}

This work was financially supported by a grant from Center for Water Quality Research, Institute for Environmental Research, Tehran University of Medical Sciences, Tehran, Iran.

\section{Author details}

'Department of Pharmaceutical Biotechnology, Faculty of Pharmacy and Biotechnology Research Center, Tehran University of Medical Sciences,
P.O. Box 14155-6451, Tehran 14176, Iran. ${ }^{2}$ Department of Environmental Health Engineering, School of Public Health, Tehran University of Medical Sciences, Tehran, Iran. ${ }^{3}$ Department of Pharmaceutical Biotechnology, Faculty of Pharmacy, Kerman University of Medical Sciences, Kerman, Iran. ${ }^{4}$ Center for Water Quality Research, Institute for Environmental Research, Tehran University of Medical Sciences, Tehran, Iran. ${ }^{5}$ Center for Solid Waste Research, Institute for Environmental Research, Tehran University of Medical Sciences, Tehran, Iran.

Received: 14 July 2013 Accepted: 2 June 2014

Published: 11 June 2014

\section{References}

1. Bayramoglu G, Gursel I, Tunali Y, Arica MY: Biosorption of phenol and 2chlorophenol by Funalia trogii pellets. Bioresour Technol 2009, 100:2685-2691.

2. Ryan D, Leukes W, Burton S: Improving the bioremediation of phenolic wastewaters by Trametes versicolor. Bioresour Technol 2007, 98:579-587.

3. Busca G, Berardinelli S, Resini C, Arrighi L: Technologies for the removal of phenol from fluid streams: a short review of recent developments. $J$ Hazard Mater 2008, 160:265-288.

4. Kim Y-J, Nicell JA: Impact of reaction conditions on the laccase-catalyzed conversion of bisphenol A. Bioresour Technol 2006, 97:1431-1442.

5. Chhaya U, Gupte A: Possible role of laccase from Fusarium incarnatum UC-14 in bioremediation of Bisphenol A using reverse micelles system. J Hazard Mater 2013, 254-255:149-156.

6. Modaressi K, Taylor KE, Bewtra JK, Biswas N: Laccase-catalyzed removal of bisphenol-A from water: protective effect of PEG on enzyme activity. Water Res 2005, 39:4309-4316.

7. Inoue M, Masuda Y, Okada F, Sakurai A, Takahashi I, Sakakibara M: Degradation of bisphenol A using sonochemical reactions. Water Res 2008, 42:1379-1386

8. Mahvi AH, Maleki A, Alimohamadi M, Ghasri A: Photo-oxidation of phenol in aqueous solution: toxicity of intermediates. Korean J Chem Eng 2007, 24:79-82.

9. Maleki A, Mahvi AH, Mesdaghinia A, Naddafi K: Degradation and toxicity reduction of phenol by ultrasound waves. Bull Chem Soc Ethiopia 2007, 21:33-38.

10. Mahvi AH, Maleki A: Photosonochemical degradation of phenol in water. Desalin Water Treat 2010, 20:197-202

11. Bazrafshan E, Biglari H, Mahvi AH: Phenol removal by electrocoagulation process from aqueous solutions. Fresenius Environ Bull 2012, 21:364-371.

12. Bazrafshan E, Mostafapour FK, Mahvi AH: Phenol removal from aqueous solutions using pistachio-nut shell ash as a low cost adsorbent. Fresenius Environ Bull 2012, 21:2962-2968.

13. Maleki A, Mahvi AH, Alimohamadi M, Ghasri A: Advanced oxidation of phenol by ultraviolet irradiation in aqueous system. Pakistan J Biol SCi 2006, 9:2338-2341.

14. Forootanfar H, Moezzi A, Aghaie-Khozani M, Mahmoudjanlou Y, Ameri A, Niknejad F, Faramarzi MA: Synthetic dye decolorization by three sources of fungal laccase. Iranian J Environ Health Sci Eng 2012, 9:27.

15. Forootanfar H, Movahednia MM, Yaghmaei S, Tabatabaei-Sameni M, Rastegar H, Sadighi A, Faramarzi MA: Removal of chlorophenolic derivatives by soil isolated ascomycete of Paraconiothyrium variabile and studying the role of its extracellular laccase. J Hazard Mater 2012, 209-210:199-203.

16. Forootanfar H, Shakibaie M, Bagherzadeh Z, Aghaie-Khozani M, Nafissi-Varcheh N, Monsef-Esfahani HR, Faramarzi MA: The removal of $\rho$-chlorophenol in aqueous cultures with free and alginate-immobilized cells of the microalga Tetraselmis suecica. J Appl Phycol 2013, 25:51-57.

17. Gholami-Borujeni F, Mahvi AH, Nasseri S, Faramarzi MA, Nabizadeh R, Alimohammadi M: Enzymatic treatment and detoxification of acid orange 7 from textile wastewater. Appl Biochem Biotechnol 2011, 165:1274-1284.

18. Gholami-Borujeni F, Faramarzi MA, Nejatzadeh-Barandozi F, Mahvi AH: Oxidative degradation and detoxification of textile azo dye by horseradish peroxidase enzyme. Fresen Environ Bull 2013, 22:739-744.

19. Gholami-Borujeni F, Mahvi AH, Naseri S, Faramarzi MA, Nabizadeh R, Alimohammadi M: Application of immobilized horseradish peroxidase for removal and detoxification of azo dye from aqueous solution. Res $J$ Chem Environ 2011, 15:217-222. 
20. Dehghanifard E, Jafari AJ, Kalantary RR, Mahvi AH, Faramarzi MA, Esrafili A: Biodegradation of 2,4-dinitrophenol with laccase immobilized on nano-porous silica beads. J Environ Health Sci Eng 2013, 10:25.

21. Sadighi A, Faramarzi MA: Congo red decolorization by immobilized laccase through chitosan nanoparticles on the glass beads. J Taiwan Inst Chem Eng 2013, 44:156-162.

22. Mogharabi M, Nassiri-Koopaei N, Bozorgi-Koushalshahi M, Nafissi-Varcheh N, Bagherzadeh G, Mohammad Ali Faramarzi MA, Faramarzi MA: Immobilization of laccase in alginate-gelatin mixed gel and decolorization of synthetic dyes. Bioinorg Chem Appl 2012, 2012:6. Article ID 823830.

23. Lu Y, Yan L, Wang Y, Zhou S, Fu J, Zhang J: Biodegradation of phenolic compounds from coking wastewater by immobilized white rot fungus Phanerochaete chrysosporium. J Hazard Mater 2009, 165:1091-1097.

24. Zhang J, Liu X, Xu Z, Chen H, Yang Y: Degradation of chlorophenols catalyzed by laccase. Int Biodeter Biodegr 2008, 61:351-356.

25. Ting WTE, Yuan SY, Wu SD, Chang BV: Biodegradation of phenanthrene and pyrene by Ganoderma lucidum. Int Biodeter Biodegr 2011, 65:238-242.

26. Uhnakova B, Petrickova A, Biedermann D, Homolka L, Vejvoda B, Bendnar P, Papouskova B, Sulk M, Martinkova L: Biodegradation of brominated aromatics by cultures and laccase of Trametes versicolor. Chemosphere 2009, 76:826-832.

27. Ostadhadi-Dehkordi S, Tabatabaei-Sameni M, Forootanfar H, Kolahdouz S, Ghazi-Khansari M, Faramarzi MA: Degradation of some benzodiazepines by a laccase-mediated system in aqueous solution. Bioresour Technol 2012, 125:344-347.

28. Forootanfar H, Faramarzi MA, Shahverdi AR, Tabatabaei Yazdi M: Purification and biochemical characterization of extracellular laccase from the ascomycete Paraconiothyrium variabile. Bioresour Technol 2011, 102:1808-1814.

29. Faramarzi MA, Forootanfar H: Biosynthesis and characterization of gold nanoparticles produced by laccase from Paraconiothyrium variabile. Colloids Surf B 2011, 87:23-27.

30. Aghaie-Khouzania M, Forootanfar H, Moshfegh M, Khoshayand MR, Faramarzi MA: Decolorization of some synthetic dyes using optimized culture broth of laccase producing ascomycete Paraconiothyrium variabile. Biochem Eng J 2012, 60:9-15.

31. Alberts JF, Gelderblom WCA, Botha A, Vanzyl WH: Degradation of aflatoxin B1 by fungal laccase enzymes. Int J Food Microbiol 2009, 135:47-52.

32. Telke AA, Kalyani DC, Jadhav UU, Parshetti GK, Govindwar SP: Purification and characterization of an extracellular laccase from a Pseudomonas $\mathrm{sp}$. LBC1 and its application for the removal of bisphenol A. J Mol Catal B 2009, 61:252-260.

33. Kurniawati S, Nicell JA: Characterization of Trametes versicolor laccase for the transformation of aqueous phenol. Bioresour Technol 2008, 99:7825-7834.

34. Okazaki S-Y, Michizoe J, Goto M, Shintaro Furusaki S, Wariishi H, Tanak H: Oxidation of bisphenol A catalyzed by laccase hosted in reversed micelles in organic media. Enzyme Microb Technol 2002, 31:227-232.

35. Chakroun H, Mechichi T, Martinez MJ, Dhouib A, Sayadi S: Purification and characterization of a novel laccase from the ascomycete Trichoderma atroviride: application on bioremediation of Phenolic compounds. Process Biochem 2010, 45:507-513.

36. Morozova OV, Shumakovich GP, Gorbacheva MA, Shleev SV, Yaropolov Al: "Blue" laccases. Biochem Mosc 2007, 72:1136-1150

37. Liu Z-F, Zeng G-M, Zhong H, Yuan X-Y, Fu H-Y, Zhou M-F, Ma X-L, Li H, Li J-B: Effect of dirhamnolipid on the removal of phenol catalyzed by laccase in aqueous solution. World J Microbiol Biotechnol 2012, 28:175-181.

doi:10.1186/2052-336X-12-93

Cite this article as: Asadgol et al: Removal of phenol and bisphenol-A catalyzed by laccase in aqueous solution. Journal of Environmental Health Science \& Engineering 2014 12:93.

\section{Submit your next manuscript to BioMed Central and take full advantage of:}

- Convenient online submission

- Thorough peer review

- No space constraints or color figure charges

- Immediate publication on acceptance

- Inclusion in PubMed, CAS, Scopus and Google Scholar

- Research which is freely available for redistribution

Submit your manuscript at www.biomedcentral.com/submit
C Biomed Central 